\title{
Testing the Waters: Drama in the Japanese University EFL Classroom
}

\author{
Eucharia Donnery
}

\begin{abstract}
This paper explores the rationale for including drama-based pedagogy into the curriculum of the Department of English at Ritsumeikan Asia Pacific University (APU) in Japan. Traditional Japanese teaching practices are explained, followed by an outline of the parallels between dramabased pedagogy and teaching practices of the Japanese elementary school. Contrary to popular expectation, drama-based pedagogy is compatible with existing traditional and cultural systems of education in Japan. Therefore, drama-based pedagogy was included in the Fundamental English language course at APU to provide the students a bridge to move from teacher-led styles of junior high and senior high schools to return to the more learner-centered styles of education of the elementary educational system. This would seem a reasonable way in which to facilitate more cooperative, rather than competitive, styles of learning. Secondly, within the course subject matter of "Intercultural Communication", drama-based pedagogy could be employed through role plays and self-reflection inside the classroom to allow the students to experience awareness of differing communicative styles when engaged in social interaction with the international students outside of the classroom. Likewise, the process of self-reflection in drama and theatre practices is a complex mix of introspective interrogation and affective engagement, which forms the catalyst for dramatic communication. The purpose of this paper is to present one specific case where drama-based pedagogy was incorporated into the English language curriculum of a rather unique Japanese university.
\end{abstract}

\section{Introduction}

\subsection{East Meets West: Styles of Education Then and Now}

Within culture, education and even martial arts, Japanese society has traditionally linked learning to veneration of masters, striving for perfection within set forms such as kabuki and karate. This Confucian-based approach is, according to Oida (1993: 203), a very old and deeply ingrained pattern in the Japanese psyche. It has a long and esteemed tradition in Japan and 
has been popularized throughout the world through martial arts and cultural pursuits such as Japanese flower arranging. Since the end of World War II, the structure of Japan's educational system has been modeled on that of the American system and is therefore divided into kindergarten, elementary school, junior high school, senior high school, two-year college and university levels. In the elementary school educational context, the teaching practices tend to be pupil-centered, active, cooperative and project-based. On graduation to the junior and senior high school levels, the emphasis becomes more focused on the procurement of knowledge for advancement by examination to the next level of the system and can be seen as more traditional and meritocratic. Against the backdrop of these environs, which are teacher-led and driven by examination results, the Ministry of Education, Culture, Sports and Technology (MEXT) has set down guidelines in 2003 that all universities in Japan should emphasize communicative approaches in English teaching over previous grammar-translation methods. While more established universities are treated with more leniency in this regard, newer universities are under the direct scrutiny of MEXT and therefore have to submit detailed curricula for approval.

\subsection{The Institutional Context: Immersive Language Education at Ritsumeikan Asia Pacific University}

The most important feature of APU is that education is bilingual; lectures with identical content are delivered in Japanese and English. Initially, Japanese students and also non-native speakers of Japanese tend to take the lecture courses in Japanese. Then, the English Department's English program provides the opportunity for students to switch linguistic bases from Japanese to English. While non-native speakers of Japanese from other regions of Asia such as Korea, China, Vietnam, Indonesia and Thailand are also encouraged to participate in the English program, most of the students are from Japan. In addition to the goal of switching linguistic bases, a more imminent concern is to endow speakers of Japanese, both native and non-native, with sufficient communicative competence to integrate with students on campus whose preferred medium of communication is English.

\subsection{Problems of the English Department}

From April 2000 until March 2005, the English Department offered contentbased learning, loosely supporting the topic areas offered by the two faculties of Asia Pacific Studies and Asia Pacific Management. However, the choice of texts and the curricular design were at the discretion of the individual English instructor, which led to vastly disparate teaching pedagogies; some instructors focused on grammar, some on reading, while more focused on academic writing. While some individual students may have benefited from this rather haphazard system, it became evident that some form of standardization was necessary for 
the good of the student body as a whole. During these years, students could enroll in the English program on an optional basis but, given that failing the option could jeopardize graduation, numbers were quite low.

The English Department was under enormous pressure to come up with solutions to three problem areas surfacing on the campus at the time:

- Due to a lack of inter-cultural mixing, tensions between the following student groups were threatening to emerge:

- The Japanese group characterized by a distinctly mono-linguistic orientation and a lack of knowledge regarding Japan's treatment of its immediate neighbours at key points during the twentieth century;

- The Korean and Chinese groups who, for historio-political reasons, appeared to be in direct opposition with the Japanese group ${ }^{1}$;

- The international English-speaking group of students predominantly from the Asia Pacific region, Africa and Eastern Europe.

The English Department regarded it as its educational mission to contribute to a reduction of these emergent antagonisms through education, negotiation and open dialogue of contentious issues between the East Asian groups. The hope was that this would subsequently facilitate a move towards mutual understanding and cultural exchange.

- The international student group was progressing from the level of beginner to proficiency in the Japanese Department within a time frame of eighteen months.

Despite teaching "false beginners" with six years of English education as opposed to novices, the English program was clearly underperforming when compared to the Japanese department. The onus was on the English Department to rectify this.

- The English Department was seen as failing to uphold the ethos on which APU prides itself, that of multiculturalism through communication, knowledge and understanding as set out in the university's mission statement ${ }^{2}$.

\footnotetext{
${ }^{1}$ The controversial issue for both groups was related to the WW II Japanese invasions into China and the colonization of Korea between the two World Wars, for which the Japanese government has not yet apologized. Fuelling the fires of racial tensions was the afore-mentioned lack of historical knowledge of the average Japanese university student, stemming from the deliberate whitewashing of Asian history in contemporary Japanese school textbooks. In 2005, there were anti-Japan demonstrations outside the Japanese embassies in Beijing and Seoul, and these kinds of displays of belligerence were beginning to seep into APU campus life.

2 "Our hope is that it will be a place where the young future leaders from countries and regions throughout the world will come to study together, live together, and understand each other's cultures and ways of life, in pursuit of goals which are common to all mankind." Taken from the Declaration on the Occasion of the Opening of APU, http://www.apu.ac.jp/home/ modules/keytopics/index.php?id=211.
} 
The restructuring of the entire English program was inevitable both from above (by the Ritsumeikan University trustees in Kyoto, the local government of Oita prefecture who had partly funded the establishment of the university, the parents' association, the Academic Office) as well as from below (by the students themselves whom the department was failing in various ways).

\section{The Arguments for Drama-Based Pedagogy in the Japanese University Classroom}

\subsection{Towards Curricular Reform}

As mentioned earlier, individual instructors were responsible for their own curricular design, its implementation, and the final evaluation of the students. This subjective approach had led to widespread complaint on the parts of the student body, responsible instructors, and the administrative office. Therefore, during the course-development meetings throughout 2004, the entire English program was standardized and redesigned for use by ALL instructors as below:-

Table 1: Standardized and Redesigned Curriculum of the English Program

\begin{tabular}{|l|l|l|l|}
\hline $\begin{array}{l}\text { Course Name / } \\
\text { Code Name }\end{array}$ & $\begin{array}{l}\text { TOEFL points } \\
\text { requirement on } \\
\text { entry and } \\
\text { departure }\end{array}$ & Focus on & Course Title \\
\hline $\begin{array}{l}\text { Fundamental } \\
\text { English I/ FE I }\end{array}$ & $400 / 450$ & $\begin{array}{l}\text { Productive } \\
\text { communicative } \\
\text { skills }\end{array}$ & $\begin{array}{l}\text { Intercultural } \\
\text { Communication }\end{array}$ \\
\hline $\begin{array}{l}\text { Intermediate } \\
\text { English I/ IE I }\end{array}$ & $450 / 500$ & Reading skills & $\begin{array}{l}\text { The Environment / Human } \\
\text { Rights }\end{array}$ \\
\hline $\begin{array}{l}\text { Advanced } \\
\text { English/ AE I }\end{array}$ & 500 on entry & $\begin{array}{l}\text { Academic skills } \\
\text { (lectures, critical } \\
\text { thinking and } \\
\text { academic writing) }\end{array}$ & $\begin{array}{l}\text { Following the student's } \\
\text { chosen faculty of either } \\
\text { Asia Pacific Studies or Asia } \\
\text { Pacific Management }\end{array}$ \\
\hline
\end{tabular}

In the fall semester of 2004, three lecturers were appointed to create, design and develop a new curriculum for the FE I course. This included a special emphasis on socio-linguistic, discursive and strategic communicative competencies. Also it was required that students make a grammatical and lexical leap of 50 points in the TOEFL component of the course, from 400 points to 450 points, within fourteen weeks ${ }^{3}$. In an effort to resolve the aforementioned issue of the three emerging groups on campus and move towards a multicultural campus envisaged in the mission statement, it was considered appropriate that the FE I course would be titled "Intercultural

\footnotetext{
3 The students at this level were composed of Japanese or international students who had at least six years exposure to English within the junior and senior high school systems and/or a TOEFL score of 400.
} 
Communication". The three different components of the course were designed to reflect the specializations of the three instructors in the different areas of intercultural education, pragmatics and drama pedagogy, the latter being solely my responsibility. The course commenced in April 2005 and continues to run unabated, albeit under constant revision. While other aspects of drama-based pedagogy such as self-reflection and vocal exercises were also included at various points in the course, the focus on situational role play was intended as:

- a means for the students to be active producers of their own knowledge and experiences rather than passive recipients of knowledge;

- a way for lecturers to evaluate the students' cognitive comprehension of complex intercultural issues.

\subsection{Cooperative Learning: The Link between Drama-Based Pedagogy and the Japanese Elementary School Education}

While contemporary Japanese society oscillates between a tradition of collectivism and a modern emphasis on individualism, within the elementary school system of education much time is spent on the development of a sense of responsibility. Contrary to the view that adherence to the group necessarily leads to passive docility, the group forms the catalyst for creativity within Japanese culture and society. In elementary schools all around Japan, after the teacher has introduced a new topic within a subject area, he or she poses open-ended questions about it to the students in a way that fosters problem-solving such as "how could X be possible?" or "I wonder if there could be any other alternatives?" Then the class is broken into smaller groups called han to work cooperatively to find possible explanations for the given problem. In each han, students appoint a group representative and work together creatively, using the input of all members of the group. Ideas are put forward without fear of ridicule; these are then carefully considered and developed by all members of the group. All opinions are valued, ensuring that all members actively participate and contribute to maintain the spirit of co-operation. As Tsuchida \& Lewis (1998:199) point out, "participation is a responsibility and not a choice" within the structure of the group in Japan. Therefore, there is no system of extrinsic rewards or of competition where there is one clear winner and many losers. Instead, the incentive for participation is in the process of learning itself. The elementary school teacher refrains from labelling students' efforts as either right or wrong, but rather allows the students to explore all possibilities and independently form their conclusions. Drama-based pedagogy echoes this style of independent learning, allowing the learners space for enquiry, cooperation and creativity. Through the role play sections of the FE I course, students were encouraged to work in groups, producing and presenting their knowledge and ideas in a creative and dynamic way.

Another feature of elementary education in Japan which has parallels with drama-based pedagogy, lies in hansei, the system of self-reflection at the end of 
every class, day and academic year. This emphasizes the societal expectation that all members take individual responsibility for active participation in the group. As in drama, the aim of self-reflection is for the pupils to create a higher awareness in relation to the learning group as well as the learning process of the individual.

Finally, another parallel can be seen in the focus on collective creation rather than on the achievements of one individual member of a group. Within the role play groups, individual students were able to profit from the safety of the group for the development of linguistic and cultural awareness through this kind of shared experiential knowledge.

\subsection{Acculturation}

Richards \& Schmidt (2002: 6) define acculturation as "a process in which change in the language, culture and system of values of a group happens through interaction with another group with a different language, culture and system of values". During the curriculum design phase of the Fundamental English course at APU all three designers drew on personal experience in language acquisition. In exploring the issue of language acquisition from personal experience, all three of us shared common experiences which indicated that when barriers to acculturation had been removed, the communicative competencies could increase significantly. According to Shi $\left(2006^{4}\right)$, acculturation, or language socialization, occurs in "any expert-novice interaction", and not just in second language acquisition. Every time a new context is entered, even within the native language, acculturation and acclimatization to new stimuli and information must occur. However, how the learner engages with them is dependent upon a variety of personal lingua-cultural issues. Schieffelin \& Ochs (1986: 172) argue that language socialization or acculturation involves a dual functionality, that of "socialization through the use of language and socialization to use language". Therefore, through the acquisition of the second language, the learner needs to be able to both tacitly and consciously understand the subtleties, rules and meanings behind that language.

According to Gardner (2001: 3), to become a competent communicator in another language involves a certain degree of integrative motivation, a desire stemming from a genuine interest in gaining psychological closeness to speakers of the target language. In a country with the historical legacy of 250 years of national isolation, there is a certain distrust of the world outside and, while this attitude is slowly changing, fluency in a foreign language is seen by many as something rather shameful within Japanese national psyche whereby to exist outside of the group through a foreign language is usually perceived as a rejection of the Japanese group itself. These attitudes and values of a bygone era have very real consequences for the learner of today. Furthermore,

\footnotetext{
${ }^{4}$ There are no page numbers as this is taken from a peer-reviewed online journal entitled "Journal of Intercultural Communication", which started by the Nordic Network for Intercultural Communication, NIC
} 
the American occupation of Japan in the aftermath of World War II and its continued presence in around 90 military bases throughout Japan present an extra layer of psychological difficulty for the Japanese learner of English in particular. And even though attitudes towards foreign language acquisition seem to be, on the surface, very positive and the study of English as a social hobby is widespread, the myriad of complex historical and psychological issues seems to form a barrier to actual control over communication within the target language of English. This forms a double bind within language learning whereby if someone can master English, then they are somehow less Japanese. This social pressure, in turn, leads to many Japanese who are fluent speakers of English to be like the proverbial eagle who "hides his talons" for fear of becoming persona non grata and, in some way, less Japanese. In contrast to these traditional attitudes, on the multi-cultural campus of APU it was essential for all students to be able to straddle the multi-linguistic and cultural norms in everyday campus life. Therefore, the acting out of various cultural phenomena was to help the learners to explore their true capacity within English and to let the learners explore their ability to decode and understand cultural information in a psychologically safe environment without fear of being relegated to the out-group.

\section{Description of Fundamental English I}

\subsection{FE I Curricular Goals - Things are to be Tried}

In the case of FE I at APU, the use of drama-based pedagogy was employed to provide students with access to more experimental and expressive uses of language both within the classroom and outside. The aims of the role play section of the course were for students:

- to be active producers and presenters of knowledge in a cooperative and creative environment without fear of being relegated to an out-group;

- to move beyond Japanese societal norms which tend to characterize cultural difference in terms of otherness, towards a more explicitly multicultural world-view;

- to develop the sensitivity and awareness to deal with various cultural differences as well as to practice issues pertaining to acculturation;

- to explore key concepts of intercultural communication;

- to have a profound experience of English within the classroom.

With these aims at its core, the role play section of the FE I course aspired to increase student motivation and enthusiasm towards the target language of English, as well as increased communicative competence. 
Within the classroom context, students produced role plays to demonstrate their understanding of each unit of the Intercultural Communication course in small groups of about four or five people. This allowed both performers and spectators to engage with the content in an accessible and dynamic way and all students to take control of their own learning.

Within the FE I course structure, their respective instructors at the start and end of each semester to evaluate their progress in fluency by interviewing all students. Each instructor also filed a class report for the role play sections during two-hour, weekly FE I meetings. Based on the lively debates at these meetings and the minutes of the two-hour weekly FE I meetings, a report was filed by the course designers examining the viability of the intercultural communication, pragmatics and role play sections. This was sent to the FE I course-coordinator, who forwarded it to the director of the English Department and the Head of the Academic Office who then sent it to MEXT for approval. In addition to these methods of on-going data collection through the class reports submitted by individual instructors in the weekly meetings and the subsequent required approvals, an open-ended e-mail questionnaire was sent to a sample group of ten students and three FE I instructors to be answered as freely and in as much depth as possible.

\subsection{FE I Intercultural Communication Outline - Pull, if it does not work when pushed}

In each semester, the FE I course consisted of 95-minute classes, four times a week, for a period of fourteen weeks. Under the title of "Intercultural Communication", the newly designed course was further subdivided into four sub-topics, each on a six-day cycle. For the role play section of the course, students were randomly assigned groups and given situations to improvise. In addition to the three aims of providing a dynamic form of learning by fostering cooperation within the class as point of departure for social discourse with the international students outside of the classroom, another objective of the role play section was for the students to productively consolidate newly acquired vocabulary and concepts. Role play was also included on the last day of the six-day cycle as part of debriefing. A sample lesson plan for one of the role play chapters entitled Aspects of Culture is as follows:

Role Play 3: Aspects of Culture:

Aims: -

- To have students practice some of the ideas studied in Unit 3 'Aspects of Culture';

- To give students an opportunity to practice dialogues;

- To give students the opportunity to practice a skill they may use in their presentations. 


\section{Procedures for Instructors -}

1. Below are five role play situations. You may select the ones you like, or use all of them. Alternatively, of course you can create your own situations (please share them!).

2. Divide class into small groups of 3-4.

3. Give each group a role play card.

4. Tell students that they must each take a role. There is some room for creativity here, for example, they can invent their age, profession, personality, sex etc. They should base their role play on the situation provided. However, if some students want to change the situation, use your discretion and by all means allow this. If students show signs of creativity and imagination, then this should be encouraged.

5. Explain that the students will be creating a dialogue, which should last for 1-2 minutes.

6. Explain that students should underline the aspect or aspects they are illustrating through their role play in the 'Aspects' column of the table. This should help them to focus on what they are doing. Tell them that they should think about the aspect(s) when working on their dialogue since these affect the language, level of politeness and so forth.

7. Give students approximately 10 minutes to work on their dialogue.

8. After 10 minutes, ask the groups to practice their dialogue and learn their lines. Encourage them to get into character.

9. As they are practicing walk around and identify the strongest or most interesting examples.

10. There may not be enough time for all the groups to perform in front of the class, so select the ones you think the whole class should see.

11. After each role play elicit responses from the class, focusing especially on the aspects of culture involved.

\section{Role Play Cards -}

\subsection{Student Reaction - He is a Person and I am a Person}

After six years of teacher-led English language education, the students of FE I were initially taken aback by the emphasis placed on role play and other learner-centered strategies, but these activities proved vital for group cohesion and cooperation. 
Table 2: Classmates Role Play Card

\begin{tabular}{|l|l|l|}
\hline Roles & Situation & Main Aspect \\
\hline classmates & $\begin{array}{l}\text { talking after being told off } \\
\text { by their teacher for } \\
\text { behaving badly }\end{array}$ & $\begin{array}{l}\text { power distance } \\
\text { individualism/collectivism } \\
\text { high/low context }\end{array}$ \\
\hline
\end{tabular}

${ }^{a}$ High power and low power distance relationships refer to the cultural differences in power stratifications and distributions. Many Western countries have quite low power distance relations in which most people consider themselves on equal footing with their superiors. On the other hand, many Asian countries have a clearly defined social stratification and tend to have a much higher power distance relationship. Examples of both behaviors can be seen at any large international airport, in a European business group, it is not always clear who is the boss while it is usually recognizable in an Asian context.

Table 4: Friends Role Play Card

\begin{tabular}{|l|l|l|}
\hline Roles & Situation & Main Aspect \\
\hline friends & $\begin{array}{l}\text { deciding what to buy } \\
\text { another friend for his/her } \\
\text { birthday }\end{array}$ & $\begin{array}{l}\text { power distance } \\
\text { individualism/collectivism } \\
\text { high/low context }\end{array}$ \\
\hline
\end{tabular}

Table 6: Members of a Family Role Play Card

\begin{tabular}{|l|l|l|}
\hline Roles & Situation & Main Aspect \\
\hline members of a family & $\begin{array}{l}\text { deciding what to do on } \\
\text { Sunday }\end{array}$ & $\begin{array}{l}\text { power distance } \\
\text { individualism/collectivism } \\
\text { high/low context }\end{array}$ \\
\hline
\end{tabular}

Table 8: Manager and Employee Role Play Card

\begin{tabular}{|l|l|l|}
\hline Roles & Situation & Main Aspect \\
\hline manager and employees & $\begin{array}{l}\text { at a supermarket, talking } \\
\text { about how to improve } \\
\text { sales }\end{array}$ & $\begin{array}{l}\text { power distance } \\
\text { individualism/collectivism } \\
\text { high/low context }\end{array}$ \\
\hline
\end{tabular}

Table 10: Two Couples Role Play Card

\begin{tabular}{|l|l|l|}
\hline Roles & Situation & Main Aspect \\
\hline two couples & $\begin{array}{l}\text { discussing where they } \\
\text { should eat }\end{array}$ & $\begin{array}{l}\text { power distance } \\
\text { individualism/collectivism } \\
\text { high/low context }\end{array}$ \\
\hline
\end{tabular}


The renowned practitioner and leading expert in the field of drama-ineducation, Fleming (1998: 149), makes the point that "real communication, particularly in public contexts with strangers may be full of sub-texts, innuendo and self-consciousness which in drama can be subject to more conscious control and manipulation". Through the use of role play in class, the significance of contextualized cultural knowledge such as proxemics, haptics, the role of silence, display of affect, gestures and other non-verbal body language, cultural norms were brought into a more interactive and more accessible setting. This intrinsic mission was to allow the learner to develop in the area of acculturation, moving beyond language as syntax to language as meaning, despite significant differences between the native and the target language. It was hoped that the language learner could begin to accommodate alternative values, norms and beliefs through language study, while simultaneously losing awareness of language as a mere mathematical code. Therefore, the main justification for the inclusion of drama pedagogy into the FE I course was that drama could provide an important point of intersection between language and acculturation within the target language of English.

\subsection{Culturally Different Communicative Styles - Not Speaking is a Flower}

In Japanese, a culture in which the vocalization of words devalue the preciousness of emotion, the pinnacle of successful communicative competence is non-linguistic. Tellingly, one Japanese FE I student called Erika commented in her online reflections the nature of Japanese linguistic culture thus:

In Japan, non-verbal communication is said to be "Ishindenshin" or telepathy. According to the dictionary, telepathy is the communication of thoughts directly from one person's mind to someone else's without speaking, writing, or signs. I like "Ishindenshin" in Japan, because it means that we can recognize each other without words. We can understand something of each other without words. For example, we regularly ask person to eat something at lunch hour without asking if that person is hungry or not. What is more, if we notice that our partner seems to want tea, salt, pen or something, we can pass it to them,.... I take pride in the Japanese culture of "Ishindenshin". ${ }^{5}$

In this culture where words are not always necessary and sometimes a mark of uncouth or childish behavior, Erika's observations about "Ishindenshin" can

\footnotetext{
${ }^{5}$ After six years of accuracy-based English education of the junior and high school systems, some universities initially refrain from making grammatical corrections of student assignments in order for the students to develop a sense of writing as a vehicle for communication interaction, rather than a system of mathematical and formulaic pattern. To foster a sense of a writing community, a Web-based discussion group was set up so the students could reflect on various aspect of culture, both Japanese and non-Japanese. The cohesive nature of the group encouraged students to post their reflections online and also to make comments about what other students had written, which seemed to demonstrate their familiarity and ease with using technology as a means of social interaction.
} 
also provide a glimpse into the sense of cohesion within the context of the Japanese identity. For intercultural communicative skills to develop, it seemed to be both necessary for the students to contemplate on and to fully understand the nature of Japanese low context cultural communicative structures, whereby the sense of a shared identity can surpass the need for verbal communication. In contrast, the high context nature of English means that much of what is understood non-verbally for the Japanese learner needs to be reconsidered linguistically. The role plays allowed the students to hone this skill of making what is non-verbal communication in one culture into a verbal one in another.

In the FE I course, role play offered the students a psychologically safe environment to explore these different communication styles. This, in turn, led to the development of the socio-cultural communicative skills necessary for meaningful acculturative ${ }^{6}$ exchange with the international students outside the classroom. The onus was on the instructor to provide the support necessary for initializing and substantiating the students' immersive experience of role play in English. Therefore, one justification for using role play in the FE I classroom was that it could maximize the input of the learner while developing social cohesion within a formal teaching situation.

Hall (1987: 10-11) attributes these differences in communicative styles to the disparity between the English and Japanese modes of communication, what he refers to as the clash between low- and high-context cultures. The Japanese language relies on empirical and shared knowledge, which is implicitly understood by other members of the Japanese community and is therefore highly contextualized as can be gathered from Erika's comment above. Information can be understood without verbalization because of the mental proximity of the Japanese amongst themselves; therefore group norms and consensus are all important. As the nature of the Japanese language is implicit, information is all around and in abundance for the average Japanese, while remaining a complete mystery to the hapless tourist or "illiterate foreigner"! Therefore, the very act of speaking English for many Japanese involves the difficulty of verbalizing much of what is unconsciously rather than overtly understood.

In contrast to Japanese, European languages are generally considered explicit or low-context languages as acquisition of all available information is necessary for comprehension. Unlike Japanese, this means that silence is not recognized as a useful tool for communication in many contexts. English speakers tend to actively seek out information and can be relentless in questioning in the pursuit of complete understanding. Within the Japanese cultural context, this can be seen as rude and intrusive as the Japanese information-seeker tends to be more circumspect and indirect. In addition to this, from the Japanese learners' perspective, English has an astonishing amount of gaps in information that the Japanese learner is reluctant to question. With this cultural dilemma in mind, one of the many aims of the FE I role play section was to offer the learners an opportunity to develop an awareness of the two culturally different

\footnotetext{
6 "Acculturative" in this article means adopting the cultural and social patterns of other groups and reframing one's own cultural identity in the process.
} 
communicative styles.

\section{Conclusions - Drama and Theatre, Doing versus Watching}

According to Fleming (1998: 148), " pupils are always ... simultaneously learning both in and through the drama" [original emphasis]. This case at hand found that use of drama-based pedagogy in the FE I English program at APU offered a bridge from traditional methods of teacher-led language education to more effective learner-led communicative competencies. Firstly, on a macro-level, it established that role play as one specific form of drama-based pedagogy can replace more linear and static forms of study prevalent at the junior and senior high school levels with a more cooperative and creative approach to learning, similar to the highly learner-centered teaching in Japanese elementary schools. In addition, outside of the classroom environment, the Japanese students made more of an effort to integrate with the international students and the Chinese and Korean students in particular, demonstrating that with increased means of communication, racial tension could be reduced. Finally, using role play in an immersive English classroom could remove fear of competition by fostering cooperation on the one hand, and on the other by building on cultural tendencies towards collectivism in a constructive way.

The economic emergence of the Asia-Pacific region has exerted pressure on Japanese society to develop English communicative competencies. In response to this need for Japan to perform on the international and Asian stage, many private universities are focusing on a more user-friendly approach to mobilize the language learner. Additionally, there are English immersive courses offered both internationally and domestically that are immensely popular. Nevertheless, the problem remains of how to construct an English-only immersion program, given that most of the learners share the same national identity. In response to this dilemma of how to motivate a class of 25 students who share a common language to speak in the target language, drama-based pedagogy within the university classroom can provide this vehicle towards the acquisition of language and its socio-cultural meaning. One particular aspect of role play, that of performance in front of classmates, seemed to provide the impetus for speaking English to fellow speakers of Japanese. Once students got used to the strangeness of using the target language to one another, it seemed to have a tremendously empowering effect and students were better able to control their English speaking. In this case, it seemed that role play could provide a safe environment in which the target language is used in a dynamic way to can relied on to create and recreate communicative experiences within real-time English linguistic and cultural contexts while concurrently giving autonomy to the learners over their own specific learning experiences and needs.

On a micro-level, role play in the FE I program provided a way for the students to use previously studied vocabulary and grammatical structures, 
while simultaneously exploring the cultural and social meanings behind words. Through this process, the FE I learners could be objective learners ${ }^{7}$, who were self-governing and in control of their own linguistic development in a non-threatening environment. This exploration of the two realities, that of the Japanese learner's social and cultural norms and that of English speakers, through role play provided a space in which the students could investigate the gaps in information that inevitably occur in intercultural discourse. Because of the performance aspect of the role plays, the FE I students were able to engage with the content material, leaving behind the shared knowledge of Japanese communicative styles, and moving into the explicit communicative styles of English with each other, thereby facilitating critical thought, creativity and reflection in the target language. This in itself brought about confidence and motivation to use their newfound skills in spoken English with the international students outside of the classroom and the gap between the two camps could be bridged. Finally, students were motivated to reframe their own Japanese reality through the eyes of others and this in turn helped them to develop both linguistic confidence and cultural sensitivity.

The benefits of using role play in the FE I English language classes at APU seemed to occur in three particular areas. Firstly, role play was an organic extension of the "han" experience during elementary school and allowed the learners to work together cooperatively on a drama-based project to develop individual creativity. Individual interviews conducted at the end of the semester indicated that this motivated the FE I learner to be pro-active learners of English, who could control their own English acquisition, rather than being Freire's empty containers awaiting the knowledge deposit of the teacher. Secondly, because of increased confidence in their English speaking skills and awareness of cultural issues, friendships were facilitated between the Japanese students and other East Asian international students in particular. Finally, the psychological gap between cultures was reduced through the effort to decode and exchange meaning both linguistic and non-linguistic.

Because of the unique nature of APU in the Japanese academic educational system, further research is necessary to determine whether drama-based pedagogy could be adapted to other university language teaching situations in Japan.

\section{Bibliography}

Altamirano, Jose (2006): Introducing the Caminando en Classe (CEC) Method. In: Polyglossi 11, 110-108

Backman, Michael; Butler, Charlotte (2003): Big in Asia. New York: Palgrave Macmillan

\footnotetext{
7 The phrase "objective learners" is used to mean that the learners could step outside their subjective views of English to explore, control and evaluate English on their own terms.
} 
Bailey, Kathleen (1983): Competitiveness and Anxiety in Adult Second Language Learning: Looking at and through the Diary Studies. In: Seliger, Herbert; Long, Michael (eds.): Classroom Oriented Research in Second Language Acquisition. Rowley: Newbury House, 163-205

Brown, H. Douglas; Gonzo, Susan (1995): Readings on Second Language Acquisition. Englewood Cliffs, NJ: Prentice Hall

Fleming, Michael (1998): Cultural Awareness and Dramatic Art Forms. In: Byram, Michael; Fleming, Michael (eds.): Language Learning in Intercultural Perspective. Cambridge: Cambridge University Press, 147-157

Freire, Paulo (1972): The Pedagogy of the Oppressed. New York: Continuum

Gardner, Robert (2001): Integrative Motivation and Second Language Acquisition. In: Dörnyei, Zoltan; Schmidt, Richard (eds.): Motivation and Second Language Research. Honolulu: University of Hawaii Press, 1-20

Hall, Edward (1987): The Hidden Dimension: Doing Business with the Japanese. New York: Doubleday

Heathcote, Dorothy; Bolton, Gavin (1998): Teaching Culture through Drama. In: Byram, Michael; Fleming, Michael (eds.): Language Learning in Intercultural Perspective. Cambridge: Cambridge University Press, 158-177

Hewfill, Denton; Noro, Hiroko; Poulton, Cody (2004): Exploring Drama and Theatre in Teaching Japanese: Hirata Oriza's Play, Tokyo Notes, in an Advanced Japanese Conversation Course. In: World Japanese Education Journal (Title is translated from Japanese, "Sekai no Nihongo Kyouiku") 14, 227-252

Kamijo, Masako (2006): Education in the "Melting Society": New Challenges facing Japanese Schools and Society. In: Mazurek, Kas; Winzer, Margret; Majorek, Czeslaw (eds.): Education in a Global Society: A Comparative Perspective. Boston, MA: Allyn \& Bacon, 371-384

Ladousse, Gillian P. (1987): Roleplay. Oxford: Oxford University Press

Mabuchi, Hiroshi (1995): The Problem of Japanology. In: Kitao, Kenji; Kitao, Kathleen; Miller, Joan Headrick; Carpenter, Juliet Winters; Rinnert, Carol (eds.): Culture and Communication. Kyoto: Yamaguchi House. 33-47

McCarthy, Michael; Carter, Ronald (1994): Language as Discourse: Perspectives for Language Teaching. London: Longman Press

Nunan, David (1989): Designing Tasks for the Communicative Classroom. Cambridge: Cambridge University Press

Nunan, David (1999): Second Language Teaching and Learning. Boston, MA: Heinle \& Heinle

Oida, Yoshi (1993): From an Actor Adrift. Asian Theatre Journal 10/2, 202-212

Oida, Yoshi; Marshall, Lorna (1997): The Invisible Actor. London: A \& C Black Publishers Limited

Oxford, Rebecca (1990): Language Learning Strategies: What Every Teacher Should Know. Boston, MA: Heinle \& Heinle 
Ritsumeikan Asia Pacific University (2000): Declaration on the Occasion of the Opening of APU.

http://www.apu.ac.jp/home/modules/keytopics/index.php?id=211. Retrieved January 17, 2008

Said, Edward (1978): Orientalism. New York: Random House

Schieffelin, Bambi; Ochs, Elinor (1986): Language Socialization. In: Annual Review of Anthropology 15, 163-191

Shimizu, Toyoko (1993): Initial Experiences with Improvised Drama in English Teaching. In: Schewe, Manfred; Shaw, Peter (eds.): Towards Drama as a Method in the Foreign Language Classroom. Frankfurt/Main: Peter Lang

Shi, Xingsong (2006): Intercultural Transformation and Second Language Acquisition. In: Journal of Intercultural Communication Volume 11. http://www.immi.se/intercultural/nr11/shi.htm. Retrieved October 11,2006

Syed, Zafar (2002): Notions of Self in Foreign Language Learning: A Qualitative Analysis. In: Dörnyei, Zoltan; Schmidt, Richard (eds.): Motivation and Second Language Acquisition. Honolulu: University of Hawaii Press, 127-148

Tomlinson, Brian (1986): Openings. London: Filmscan/ Lingual House

Tsuchida, Ineko; Lewis, Catherine (1998): Hypotheses about Japanese Elementary Classrooms. In: Rohlen, Thomas; LeTendre, Gerald (eds.): Teaching and Learning in Japan. Cambridge: Cambridge University Press

Wessels, Charlyn (1987): Drama. Oxford: Oxford University Press

Wright, Walter (1998): Cultural Issues in Mediation: A Practical Guide to Individualist and Collectivist Paradigms. In: Texas: The Association of Attorney-Mediators. http://www . attorney-mediators.org/wright.html. Retrieved July 9, 2007

Yoneyama, Shoko (1999): The Japanese High School: Silence and Resistance. London: Routledge 


\section{A Terms and Abbreviations}

\begin{tabular}{|l|l|}
\hline Elementary school & $\begin{array}{l}\text { Equivalent to the Irish primary school system, albeit for six } \\
\text { years rather than eight. Examinations are taken in order to } \\
\text { progress to the more prestigious junior high schools. }\end{array}$ \\
\hline Junior high school & $\begin{array}{l}\text { Three years in length. Examinations are taken by all in } \\
\text { order to progress to the next level of education. }\end{array}$ \\
\hline Senior high school & $\begin{array}{l}\text { Three years in length. Examinations are taken by all in } \\
\text { order to progress to the next level. }\end{array}$ \\
\hline Junior college & $\begin{array}{l}\text { Two years in length. Equivalent to an Irish post } \\
\text { Leaving-Cert course. }\end{array}$ \\
\hline Japanese universities & $\begin{array}{l}\text { Four years in length. There are national universities that } \\
\text { are held in high esteem, so competition for entry is fierce. } \\
\text { Private universities command higher fees and can vary in } \\
\text { quality from finishing-school level to an extremely } \\
\text { competitive academic level. }\end{array}$ \\
\hline APU & $\begin{array}{l}\text { Ritsumeikan Asia Pacific University, a private and academic } \\
\text { university. In existence since } 2000 \text { and situated on Kyushu, } \\
\text { the most southerly of the four main Japanese islands. }\end{array}$ \\
\hline FE I & $\begin{array}{l}\text { Fundamental English I. A course designed for students with } \\
\text { six years exposure to English and/or a TOEFL score of 400. }\end{array}$ \\
\hline MEXT & $\begin{array}{l}\text { The Japanese Ministry of Education, Culture, Sport and } \\
\text { Technology. }\end{array}$ \\
\hline TOEFL & $\begin{array}{l}\text { The Test of English as a Foreign Language. The most } \\
\text { common marker of English language proficiency by } \\
\text { colleges and universities worldwide. }\end{array}$ \\
\hline
\end{tabular}

